REVISTA DEL POSGRADO EN DERECHO DE LA UNAM | revistaderecho.posgrado.unam.mx AÑO 7, N 12, ENERO - JUNIO 2020 | https://doi.org/10.22201/fder.26831783e.2020.12.141

\title{
ANÁLISIS HISTÓRICO Y JURÍDICO DEL CONTROL EXTERNO DE LA ADMINISTRACIÓN PÚBLICA EN MÉXICO, COLOMBIA Y ECUADOR
}

\author{
Historical and legal analysis of external control of \\ PUBLIC ADMINISTRATION IN MEXICO, COLOMBIA AND ECUADOR \\ GuIDO FERNANDO ESCOBAR PÉREZ ${ }^{*}$
}

Resumen: Los Estados surgieron por la decisión exclusiva de las clases dominantes con la finalidad de legitimar y consolidar su poder, el mismo que en sus inicios no tuvo límites, degenerándose por los excesos. En este punto de la historia surge la necesidad de controlar al poder dentro de una dinámica de pesos y contrapesos. Cada organización social, atendiendo sus realidades sociales, económicas y culturales fue desarrollando y proponiendo un sistema de control administrativo del Estado y utilizando varios mecanismos técnicos para esos efectos. En este proceso histórico sin lugar a dudas tuvieron una gran influencia los países que nos conquistaron, en virtud de la escuela greco romana, así como los grupos de poder en cada Región y la exacerbada crisis económica de las nacientes repúblicas; luego de nuestras luchas por la independencia que de manera coincidente se dieron a inicios del siglo XVIII, bajo una fuerte influencia política del ideario de la revolución francesa de 1789 . El estudio comparado de los antecedentes históricos y jurídicos de México, Colombia y Ecuador, nos permiten establecer que existen rasgos coincidentes cuando las repúblicas hermanas nacen como repúblicas independientes en los sistemas de control gubernamental, pero con el pasar del tiempo y en atención a sus propias realidades van variando por la influencia de otras escuelas jurídicas como la anglosajona.

Palabras clave: Poder; control administrativo; escuelas jurídicas; derecho comparado; Administración Pública.

Abstract: States arose by exclusive decision of the ruling classes to legitimize and consolidate their power, just as at the beginning it had no limits, degenerating from excesses. At this point in history, it is necessary to control power within a dynamic of weights and counterweights. Each

${ }^{1 *}$ Doctor en Jurisprudencia por la Universidad Central del Ecuador y Magíster en Derecho Administrativo por la Universidad Andina Simón Bolívar, Docente en la Maestría de Gestión Pública Universidad Católica del Ecuador. <gjgescobar@hotmail.com>. ORCID: < https://orcid.org/0000-0002-1654-5203>.

Fecha de recepción: 5 de octubre de 2019; Fecha de aprobación: 27 de enero de 2020. 
social organization, attending to its social, economic and cultural realities, was developing and proposing a system of administrative control of the State and using various technical mechanisms for these purposes. In this historical process, without a doubt, the countries that conquered us, by virtue of the Greco-Roman school, as well as the power groups in each Region and the exacerbated economic crisis of the nascent republics had a great influence; after our struggles for independence that happened casually in the early eighteenth century, under a strong political influence of the ideology of the French Revolution of 1789. The comparative study of the historical and legal backgrounds of Mexico, Colombia and Ecuador, allow establish that there are coincident characteristics when sister republics are born as independent republics in government control systems, but over time and in attention to their own realities, they vary according to the influence of other legal schools such as Anglo-Saxon.

Keywords: Power; administrative control; legal schools; comparative law; Public administration.

Sumario: I. Introducción; II. Antecedentes históricos de la región; III. Los marcos jurídicos; IV. Conclusiones; V. Fuentes consultadas.

\section{I NTRODUCCIÓN}

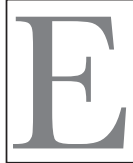

l poder institucionalizado se manifiesta a través de dos funciones esenciales: a) gobierno y b) control$^{2}$, sin embargo, estas funciones son caras de una misma moneda, porque nacen del propio poder del Estado con potestades coercitivas. Controlar el poder es un acto de poder. El control no se ejerce para destruir o sustituir al poder, se ejerce por el propio poder para su mantenimiento. ${ }^{3}$

La actividad de control comprende los mismos elementos que la actividad de gobierno, solo que la primera tiene una característica específica, que es la de verificar los medios (el cómo) y los fines (el

2 Dromi Roberto, Derecho Administrativo, Tomo I, Buenos Aires, Hispana Libros, 2015, p. 222.

${ }^{3}$ Valadés Diego, El control del poder, México, Universidad Nacional Autónoma de México, IIJ, 2006, p. 17. 
para qué $)^{4}$, confronta la razonabilidad de los medios utilizados para alcanzar los fines, sobre parámetros de eficiencia, eficacia, economía, moralidad y sustentabilidad. El control verifica que esos fines se hayan cumplido efectivamente, y propone los elementos correctivos en caso de desvíos.

$\mathrm{Si}$ "el poder corrompe, y el poder absoluto corrompe absolutamente", como se destaca en la citada frase de John Emerich Acton, entonces históricamente el control ha sido una gran herramienta de defensa de la sociedad frente a los abusos del poder, para generar lazos de conciliación entre los diferentes grupos sociales, por cuanto en la dinámica social y política de inclusión y exclusión que se verifica en la lucha por el poder, en la lucha contra el poder y en la lucha desde el poder. Lo que en el fondo se agita es la preocupación secular por evitar los excesos del poder, independientemente de las contradicciones semánticas que suponga, separar los poderes o aludir a la función o servicio público, controlar el poder es una necesidad social para la subsistencia de la libertad. ${ }^{5}$

De manera general el control es mirado como una herramienta de defensa de la sociedad en contra de las arbitrariedades del poder, el mismo que se impone para asegurar la sujeción del obrar público al marco jurídico, así como el cumplimiento de sus metas y objetivos. Entonces el control es un medio efectivo para materializar los derechos subjetivos de los ciudadanos, de cuyo cumplimiento depende la confianza y seguridad pública, lo cual consolida o no la propia institucionalidad del Estado y la Democracia. Cuando el control se desnaturaliza es mirado como la más perversa herramienta de persecución en contra de quienes piensan diferente a los gobernantes de turno, en razón de que el control es parte del propio poder y en lugar de cumplir su misión de equilibrio social, torna a las relaciones caóticas, poniendo en riesgo la institucionalidad del Estado. Algunos actores públicos utilizan los resultados de

\footnotetext{
${ }^{4}$ Dromi Roberto, op. cit., p. 225.

${ }^{5}$ Valadés Diego, op. cit., pp. 2, 3.
} 
los órganos contralores para justificar su actividad o para descalificar al adversario. ${ }^{6}$

El objetivo central del control administrativo es evaluar la razonabilidad de las operaciones administrativas y financieras de las instituciones públicas, el cumplimiento eficiente y efectivo de sus metas y objetivos, que se expresa en un informe, en procura de mejorar la gestión de la maquinaria estatal; y por excepción frente al hallazgo de irregularidades determinar responsabilidades. La actividad de control se desarrolla en el derecho público y administrativo, la potestad de determinar responsabilidades constituye complemento de la facultad correctiva del sistema de control, no su fin.

Existe una contradicción entre control y corrupción, el control tiene como pretensión eliminar, detener, evitar la corrupción; En cambio la corrupción busca superar los controles y obtener ganancias y beneficios ilícitos, y a partir de este proceso conseguir impunidad. En un sentido dialéctico, mientras la tesis es la corrupción, la antítesis es el control y la síntesis es la restauración o restitución al Estado de Derecho. ${ }^{7}$ Desde el punto de vista jurídico el control es una herramienta de carácter normativo que permite generar dos grandes causes dentro de la toma de decisiones públicas.

El primer gran cause es sujetar todo el aparato de la administración al principio de legalidad, la norma es un estándar a partir del cual, cuando se ejerce una función pública se puede advertir que se respetan ciertos estándares de acción, por un lado, pero también se logren fines. En sentido procesal o adjetivo, como un conjunto de normas, reglas y principios que establece quien toma las decisiones públicas y bajo qué procedimientos. Y desde el segundo punto de vista, el represivo genera un entorno que permite que quien haya infringido la ley sea en alguna medida, sujeto a las sanciones que la norma prescribe.

${ }^{6}$ Márquez Gómez, Daniel. Función Furídica de Control de la Administración Pública. México Universidad Nacional Autónoma de México, IIJ, 2005. p. XIX.

${ }^{7}$ Márquez Gómez, Daniel, Entrevista en el Instituto de Investigaciones furídicas de la Universidad Nacional Autónoma de México, Ciudad de México, 20 septiembre de 2018. 
Como insumos para el ejercicio del control tenemos los informes de rendición de cuentas, introducidos desde la década de los 90 a partir de los acuerdos sobre revitalización administrativa de la ONU, que también entran al contexto del gobierno de lo visible por un lado, y por el otro lado, la obligación de los gobiernos de mostrar lo que se hace dentro de él, acorde a lo previsto en la declaración de los derechos del hombre y del ciudadano de 1789: Todo ciudadano tiene derecho de pedir cuentas de su gestión a todo agente público. El control social en la práctica es un control de apoyo o coadyuvante del control técnico de la administración orientado a legitimar el accionar público como ejercicio del derecho a la participación ciudadana, en la tarea de vigilancia y fiscalización de los órganos de gobierno. La clave de su desarrollo está en transparentar los procesos de participación social y castigar el ocultamiento de información institucional de parte de las Autoridades; así como regular y castigar uno de los disfraces más comunes de la corrupción como son la calificación de reserva o confidencialidad de la documentación pública.

Kart Loewenstein en su obra "Teoría de la Constitución" señala que constitución y control son intercambiables, si el gobierno solamente puede emerger de un pacto jurídico político expresado en la constitución, tendríamos que aceptar que la constitución es el control del poder en la medida en que es capaz de poner límites y desde esa perspectiva la institucionalización derivada del instrumento constitucional podría entenderse básicamente como el control de toda la función de gobierno. Agrega que existen controles horizontales y verticales. A su vez, los controles horizontales se clasifican en intraorgánicos e interorgánicos; los primeros operan dentro de la organización de un solo detentador del poder, su objetivo es limitar y vigilar el funcionamiento de esa organización; los segundos funcionan entre los diversos detentadores del poder que cooperan en la gestión estatal, por lo que norman y limitan recíprocamente el funcionamiento de dos o más órganos del poder público. Entre los 
controles verticales tenemos los derechos individuales y las garantías fundamentales. ${ }^{8}$

Desde este punto de vista, si la Constitución es el "control del poder", entonces tenemos que en el Estado democrático, el poder tiene un sentido estrictamente político, porque derivada de la herramienta que es la base de la institucionalidad, es decir, de donde emerge la sociedad política, o sea, de la base del mismo "poder" político: la constitución.

II. Antecedentes Históricos DEL CONTROL EN LA REGIÓ N

Se ha dicho que el control sobre los recursos públicos está presente desde el descubrimiento de América y la conquista, aunque, en estricto rigor, en esta época dicha vigilancia se ejercía sobre el manejo de los bienes de la Corona o del Monarca y no sobre los bienes del Estado9. Como se advierte, el control en su dimensión política no es una institución novedosa, tiene fuertes raíces en La Colonia, sin embargo, no olvidamos que antes de la llegada de los españoles ya existía control, sin embargo, no queremos extendernos demasiado en los antecedentes históricos.

En efecto, cuando se produce el descubrimiento de América se implanta de manera simultánea un sistema de vigilancia -o de control fiscal, según la asimilación anunciada- sobre los fondos o bienes de la Corona. Así las cosas, en el segundo viaje de Cristóbal Colón, cuando parte de Cádiz al frente de una empresa colonizado-

${ }^{8}$ Loewenstein Karl, Teoría de la Constitución, 2a . ed. España, Ariel, 1976, pp. 232-235.

${ }^{9}$ Como bien lo afirma Younes Moreno en su obra Régimen de Control Fiscal, Bogotá, Temis, 1987, p. 55, en ese entonces el interés era la vigilancia de los dineros del Monarca, no del Estado, por lo cual no es acertado hablar de un control fiscal, entendido como el derecho de la comunidad para fiscalizar los dineros públicos que administra el Estado. Esta distinción se define con claridad en la Revolución Francesa. 
ra ${ }^{10}$ conformada por 17 naves y 1500 personas, los Reyes Católicos designan un funcionario con la misión de vigilar el manejo de los fondos y bienes de la expedición. Dicho funcionario se denominó "lugarteniente de los Contadores Mayores de Castilla".

Posteriormente, con la fundación de Santo Domingo por parte de Bartolomé Colón -hermano del primer almirante de las Indias-, y debido a sus fracasos políticos y a la mayor complejidad de la administración de los territorios ocupados, se organiza el Tribunal de la Real Audiencia de Santo Domingo (1511). En ese entonces, el hijo del Descubridor, Don Diego Colón, ejercía el Gobierno de La Española (como se llamó a la isla antillana).

Este Órgano corporativo de la administración de justicia ejerció de la misma manera, funciones de gobierno, entre las cuales se destaca la labor de vigilancia a los altos funcionarios de la Corona, incluyendo la de fiscalizar a los virreyes. A través de los juicios de residencia se ordenaba, entre otros aspectos, la rendición de cuentas sobre los bienes fiscales, puesto bajo la administración de los funcionarios, principalmente cuando se retiraban de sus cargos. Esta audiencia fue suprimida en 1513, debido a los conflictos jurisdiccionales presentados con Don Diego Colón; se restableció en 1516, se suprimió luego, para finalmente ser restablecida en forma definitiva en 1526; "y ya desde entonces se generalizó esta institución en tierra continental, creándose nuevas audiencias a medida que así lo requerían los avances de la conquista" ${ }^{11}$.

En 1518 se constituyó en forma permanente el Consejo de Indias, configurando como el supremo órgano administrativo colonial. Además de ser el órgano de consulta para todos los asuntos referentes a las Indias, ejercía funciones del cuerpo legislativo y

${ }^{10}$ Gómez Latorre, Armando. Antecedentes históricos de la Contraloría, en Economía Colombiana, Revista de la Contraloría General de la República, núm. 150, Bogotá, 1983, p. 52.

${ }^{11}$ Otscapdequi, J.M., El Estado Español de las Indias, México, Fondo de Cultura Económica, 1982, p. 58. 
máximo tribunal de apelación en asuntos contenciosos, civiles, administrativos y criminales ${ }^{12}$.

En el año de 1604 se crearon los Tribunales de Cuentas, especialmente en las regiones donde se explotaban metales y piedras preciosas, en razón a lo representativo de los ingresos de la Corona. "Durante el siglo XVII y gran parte del XVIII, los Tribunales de Guentas hicieron las veces de contralorías regionales en los virreinatos, capitanías y presidencias en que España había divido política y administrativamente su imperio colonial en América ${ }^{13}$ ".

Así, se crearon los tribunales de cuentas, esencialmente donde se daba la explotación minera, donde más ingresos representaba para la Corona. Mediante las ordenanzas promulgadas en Burgos el 24 de agosto de 1605, Felipe III fundó estos tribunales en América, con sedes en las ciudades de México, Lima y de Santa Fe de Bogotá y su jurisdicción coincidiría con la del Virreinato respectivo. Dichos Tribunales tenían por objeto tomar y finiquitar las cuentas que presentaran los oficiales reales y demás encargados de recaudar y administrar las rentas de la corona (tesoreros, arrendadores, administradores, fieles y cogedores de rentas reales), también conocían sobre el cobro de los retrasos en el pago de las deudas al fisco, conforme a los procedimientos que con ese propósito aplicaba la Contaduría Mayor de Cuentas de Castilla. ${ }^{14}$

Así, estas instituciones novohispanas serán la base del control del control en la región, por lo que es necesario destacar, muy someramente, cómo funcionaba el control en Colombia, México y Ecuador.

${ }^{12}$ Jaramillo Uribe, Jaime. Manual de historia de Colombia, Bogotá, pro cultura Instituto Colombiano de Cultura, 1982, p. 356.

${ }^{13}$ Idem.

${ }^{14}$ Idem. 
1. Reseña histórica del control gubernamental en COLOMBIA

Luego de las guerras por la independencia y su ascenso a la misma en los países de Latinoamérica, se producen grandes crisis económicas, políticas, sociales y jurídicas, pues la misión de destruir el estatus quo para reconstruir absolutamente todo, significó un gran esfuerzo para las Repúblicas nacientes.

Al culminar el movimiento insurgente e iniciar su vida independiente, las naciones que surgían enfrentaban problemas derivados de su reciente creación, inherentes a ser un país nuevo, en el cual, desde el punto de vista político, todo estaba por hacerse. Y porque había ideas distintas respecto a cómo hacerlo, la primera etapa de la vida independiente se caracterizó por una gran inestabilidad política. Ello repercutió directamente en el manejo de las finanzas públicas $^{15}$

Además de lo señalado las nacientes repúblicas heredaron un sistema tributario inviable para sus pueblos (Alcabalas, prohibiciones, diezmos, estancos, monopolios, bienes clericales) lo cual condicionaba la banca rota de sus economías que duró más de un siglo con las consiguientes consecuencias sociales en perjuicio de nuestros pueblos.

Concomitante con lo señalado entre los años 1923 y 1926, en Colombia y Ecuador, los avatares de sus economías posterior a la Primera Guerra Mundial y reflejados en una elevada inflación, continuos déficits presupuestarios, manejo irresponsable de la emisión por parte de los bancos privados, unidos a las dificultades en el comercio internacional con sus productos de exportación, obligaron y generaron consenso a nivel nacional e internacional sobre la necesidad de revitalizar sus economías. En aquellos años existió una

${ }^{15}$ Solares Mendiola Manuel, La auditoría Superior de la Federación: Antecedentes y Perspectiva furídica, México, Universidad Nacional Autónoma de México, IIJ, 2004, p.29. 
corriente internacional encaminada a la reorganización de la economía mediante la adopción del patrón oro en base a un organismo como el Banco Central que se encargaría de vigilar su cumplimiento. En general la creación de bancos centrales y el fortalecimiento de los sistemas bancarios, fue el instrumento utilizado para llevar a cabo la estabilización de los cambios y frenar la inflación en que habían quedado sumidos varios países al finalizar la Primera Guerra Mundial. Precisamente durante la década de los veinte el doctor Edwin W. Kemmerer encabezó varias misiones y fue el encargado de crear estas instituciones en algunos países sudamericanos. Estos bancos funcionaban en el marco del patrón oro, tendrían el monopolio de la emisión de billetes, determinaran el tipo bancario, llevarían a cabo operaciones en el mercado libre y actuarían en calidad de prestamistas de último recurso. Su reforma fue de carácter integral, pues incluso se diseñaron proyectos encaminados a la reorganización fiscal, restauración del crédito nacional, reformas bancarias y de obras públicas, entre ellas, la creación de Sistemas de Control Gubernamental, a cuyo efecto se propone la creación de la Contraloría General del Estado, a efectos de fiscalizar de mejor manera los ingresos y gastos públicos. ${ }^{16}$

Al hablar de la evolución del Control Fiscal, es preciso referirse a la Misión "Kemmerer" realizada entre 1919 y 1931, donde el profesor Edwin Walter Kemmerer, realizó diversas propuestas a los gobiernos de Bolivia (1928), Chile (1925), Colombia (1923), Ecuador (1926), Guatemala (1919), México (1917) y Perú (1930), en materia monetaria, bancaria y fiscal. ${ }^{17}$

${ }^{16}$ Consulta: 29 de noviembre de 2019 https://biblio.flacsoandes.edu.ec/catalog/ resGet.php?resId=53323.

17 Véase: Gozzi, Eugenia, Tappatá, Ricardo, La misión Kemmerer. Primera iniciativa de reforma financiara profunda en América Latina, en: http://fitproper. com/documentos/propios/Mision_Kemmerer.pdf, consultado el 4 de noviembre de 2019 . 
En Colombia, el presidente Pedro Nel Ospina contrató a los expertos de Kemmerer, esa comisión recomendó crear un organismo de contabilidad, fiscalización y estadística que permitiera al país poner en orden sus finanzas y ejercer la vigilancia en el manejo de la inversión del erario público. Se concreta entonces, la Ley 42 de 1923 sobre la reorganización de la contabilidad oficial y la creación de las Contralorías Territoriales. ${ }^{18}$

La Constitución Política de Colombia de 20 de julio de 1991, inicia una nueva era del Control Fiscal cuando enriquece el ejercicio de ese control con instrumentos que permiten medir la eficiencia, eficacia, economía, equidad, valoración de los costos ambientales y, en general, la gestión fiscal del Estado; superándose así la etapa del simple control numérico legal. ${ }^{19}$.Entre los aspectos más importantes contemplados en esta gran reforma que desarrolla la Constitución, se presenta el abandono definitivo del control Previo, que desde la Ley 42 de 1923, venía presentando tímidas reformas para pasar a un Control Posterior y Selectivo en la vigilancia de la gestión fiscal del Estado, a través de controles como el financiero, de gestión y de resultados que permiten conceptuar sobre el cumplimiento de los principios fiscales y el manejo de la Administración Pública. Así, esa ley fundamental permitía: el derecho ciudadano de participar en el control político (art. 40); asignaba al Congreso el control político sobre el gobierno y la administración (art. 114); y asignaba al ministerio público y a la contraloría general el carácter de órganos de control (art. 117).

La Ley 20 de 1975 y sus Decretos Reglamentarios, establecen el control fiscal posterior que a partir de la Constitución de 1991 y luego con la expedición de la Ley 42 de 1993, se denomina control posterior y selectivo, delimitando el accionar de las Contralorías.

${ }^{18}$ Ibídem, p. 4.

${ }^{19} \mathrm{El}$ profesor Uriel Alberto Amaya muestra de una forma más detallada la historia de la República en su libro la Teoría de la Responsabilidad Fiscal. Aspectos sustanciales y procesales, Universidad Externado de Colombia, 2002, pp. 48- 43. 
Aparecen definidos los sistemas de Control Fiscal como el de legalidad, físico, financiero, control de gestión y resultados, evaluación de control interno y valoración de costos ambientales; fundamentados en los principios de eficiencia, eficacia, economía y equidad" ${ }^{20}$.

Según el maestro Jorge Hernán Betancur los Constituyentes de 1991, luego de un estudio ponderado con base en la experiencia del control previo, perceptivo y posterior de las auditorías de orden nacional, departamental y municipal, concluyeron sobre los peligros que ello venía presentando ante la eventual co-administración ${ }^{21}$, unas veces sana, pero en otras, cómplice de la corrupción administrativa legalizada en la simple función verificadora, que se venía realizando al confrontar datos plasmados en formatos preestablecidos por los departamentos de organización y métodos; en otras ocasiones, las auditorías eran simples entorpecedoras de los actos administrativos y de sus gestiones operativas con graves consecuencias para el desarrollo de los planes, programas y políticas de las empresas auditadas, o de los objetivos que en forma eficiente debían cumplir las entidades oficiales.

Entonces el control previo era sinónimo de impunidad, si las auditorías daban su visto bueno previamente y se producía un mal manejo de los bienes del Estado no habría lugar a reclamación posterior. Siendo de igual forma un entorpecedor de las misiones institucionales de forma eficiente y efectiva. En un estudio coordinado por Fernando Cepeda Ulloa se afirma que: los sistemas de control

${ }^{20}$ Para realizar una consulta más detallada sobre el tema se puede consultar en línea la página de la contraloría de Manizales en el link < http://www.contraloríamanizales.gov.co/n_portal/index.php? option =com_content\&view $=$ article\&id $=20 \&$ ite$\operatorname{mid}=20>$.

${ }^{21}$ Para el profesor Iván Darío Gómez Lee es acertada la decisión de los Constituyentes 1991 de prohibir la coadministración. Y seguidamente nos dice que la constitución erige un control a la gestión de recursos públicos fundados en disciplinas de auditoría, que superan el concepto tradicional de rendición de la cuenta, complementando con criterios de evaluación integral de la gestión y los resultados. Página 48. Universidad Externado de Colombia Edición agosto de 2006. 
se basaron en el pasado en el principio del control previo (la expedición de la Constitución de 1991 podría ser señalada como el momento del cambio hacia un nuevo esquema de control posterior). En los hechos, el control previo terminó por convertirse en una talanquera (valla, pared, o parapeto defensivo) para la eficacia de la administración y en una fuente de corrupción. ${ }^{22}$ Como se advierte, el control en ese instrumento constitucional era disfuncional.

\section{Antecedentes históricos del control gubernamental EN MÉXICO}

El 22 de octubre de 1814 se emitió el Decreto Constitucional para la Libertad de México, conocido como la Constitución de Apatzingán, en cuyo texto consta el primer antecedente constitucional sobre la facultad de examinar y aprobar la cuenta pública por parte de un órgano distinto e independiente del Poder Ejecutivo: “(...) $\mathrm{Al}$ Supremo Congreso pertenecen exclusivamente...Examinar y aprobar las cuentas de recaudación e inversión de la Hacienda Pública $(\ldots) " .23$

En materia de hacienda pública, se expidió, en 1824, la ley para el "Arreglo de la Administración de la Hacienda Pública" con la que se creó un Departamento de Cuenta y Razón, la Tesorería General de la Federación y la Contaduría Mayor de Hacienda y Crédito Público. En 1830 se amplían las atribuciones de la Tesorería y en 1831 se establecen la Dirección General de Rentas y las Comisarías Generales de Hacienda, Crédito Público y Guerra. En 1851 se reorganizó la hacienda pública y se ordenó llevar la contabilidad

${ }^{22}$ Véase: Las causas de la corrupción, en Semana, sección Nación, 9/19/1994, en: https://www.semana.com/nacion/articulo/las-causas-de-la-corrupcion/23515-3, consultado el 4 de diciembre de 2019. La frase entre paréntesis es mía.

${ }^{23}$ Solares Mendiola, Manuel. La auditoría Superior de la Federación: Antecedentes y Perspectiva Jurídica, México, Universidad Nacional Autónoma de México, IIJ, 2004, pp. 28-29. 
por partida doble. En 1853, en el gobierno de Antonio López de Santa Ana, se centralizó la materia hacendaria, creando la Dirección General de Impuestos, y se cambió a la Contaduría Mayor en Tribunal de Cuentas. En 1855, la Secretaría de Hacienda reasume las atribuciones que tenía la Dirección General de Impuestos y se restablece la Contaduría Mayor de Hacienda ${ }^{24}$

En el Congreso Constituyente de 1857 de México, prevaleció el liberalismo clásico, es decir, la no intervención del Estado en el desarrollo económico; con las deliberaciones del Congreso Constituyente de 1917 se diseña el rostro social de la Revolución, se cancelan injustas y arcaicas estructuras políticas y económicas, se establecen nuevos mecanismos de redistribución del ingreso e intervención estatal. Así se abandona el liberalismo clásico y se adopta una participación activa del Estado en la vida económica del País. ${ }^{25}$ Es natural que los constituyentes mexicanos, al inicio de la vida independiente, hayan tenido muy presente la experiencia de la Constitución de Cádiz, y las de Estados Unidos y Francia. No puede decirse que se trataba de un proceso imitativo, sino de una muy normal forma de influir ya por la similitud de intereses, ya por afinidades históricas, inclusive se llegó a proponer que la Constitución de Cádiz se adoptará como ley ordinaria en México, para integrar supletoriamente las lagunas de la norma suprema mexicana. Los términos de la influencia estuvieron determinados por la universalidad de las ideas que comenzaban a permear las instituciones de derecho público en diferentes países; por la comunidad de intereses entonces existentes con España; por la convergencia de luchas políticas, que también hacía frente a la reafirmación de su independencia ante Francia; por la fuerte relación humana sostenida entre los miembros de las nacientes élites políticas mexicana y española, y por la asociación de la lucha armada y los procesos electorales en el territorio mexi-

\footnotetext{
${ }^{24}$ Márquez Daniel, op. cit., pp. 2-3.

${ }^{25}$ Solares Mendiola, Manuel, op. cit., pp. 20-31.
} 
cano. La presencia de algunas disposiciones españolas se identifica en diversos textos constitucionales mexicanos, hasta la actualidad. ${ }^{26}$

En 1881 se dan atribuciones de fiscalización a la Tesorería. La revolución mexicana de 1910 incorpora los derechos sociales a la Constitución; por enésima vez, se reorganiza la Tesorería y se crea la Dirección de Contabilidad y Glosa dependiente de la Secretaría de Hacienda y Crédito Público. ${ }^{27}$

En 1917, el presidente Venustiano Carranza estableció el Departamento de Contraloría General de la Federación, que contaba con un órgano de Auditoría General. En 1926 se expidieron las Leyes Orgánicas del Departamento de Contraloría de la Federación y de la Tesorería de la Federación, la primera tenía la encomienda de encargarse del llamado control previo. En 1932 se suprimió el Departamento de la Contraloría. Entre 1933 y 1947 correspondió a la Secretaría de Hacienda y Crédito Público ejercer las funciones de control; entre otras, se encargó de la contabilidad general de la Federación y de la imputación y registro de las responsabilidades administrativas detectadas al glosar las cuentas. En 1940 se emite la "Ley de Responsabilidades de los Funcionarios y Empleados de la Federación, del Distrito y Territorios Federales y de los altos funcionarios de los Estados" y en 1936 se creó el Tribunal Fiscal de la Federación. Durante el periodo que comprende los años de 1947 a 1958 corresponde a las Secretarías de Hacienda y Bienes Nacionales e Inspección Administrativa ocuparse de la materia del control. ${ }^{28}$

Entre 1959 a 1976 las tareas de control se dividen entre la Secretaría de Hacienda y Crédito Público, la Secretaría de la Presidencia y la Secretaría de Patrimonio Nacional. En 1976, al expedirse diversas leyes, entre ellas la Ley Orgánica de Administración Pública Federal y la de Presupuesto, Contabilidad y Gasto Público Federal,

\footnotetext{
${ }^{26}$ Valadés Diego, op. cit., pp.337-339.

${ }^{27}$ Idem.

${ }^{28}$ Ibidem, p.4.
} 
el control de la administración pública se encomienda a la Secretaría de Programación y Presupuesto. En 1982, se crea la Secretaría de la Contraloría General de la Federación, anterior Secretaría de Contraloría y Desarrollo Administrativo actual Secretaría de la Función Pública, como ente globalizador del control interno de la administración pública en el ámbito federal. En este año, después de una amplia reforma al título cuarto de la Constitución Política de los Estados Unidos Mexicanos, surge a la vida jurídica la Ley Federal de Responsabilidades de los Servidores Públicos ${ }^{29}$

En este sentido, a partir del 28 de diciembre de 1982, el control interno le correspondía a la Secretaría de la Contraloría General de la Federación, mientras que el control externo lo ejercía la Contaduría Mayor de Hacienda de la Cámara de Diputados, regulada en el artículo 74, fracción IV, de la Constitución Política de los Estados Unidos Mexicanos, como órgano técnico de la Cámara de Diputados, con la función de revisar de manera posterior la llamada "cuenta pública".

En 1983 la Constitución, tercer inciso del artículo 26 señala: “... La ley facultará al ejecutivo para que establezca los procedimientos de participación y consulta popular en el sistema nacional de planeación democrática, y los criterios para la formulación, instrumentación, control y evaluación del plan y los programas de desarrollo...". El control externo de la administración pública corresponde al Congreso de la Unión desde que nació México como República. Para ejercer este control el Poder Legislativo específicamente la Cámara de Diputados, contó con un órgano técnico que era la Contaduría Mayor de Hacienda, creada en 1824, que fue sustituida desde el año de 1999 por la actual Auditoría Superior de la Federación ${ }^{30}$. Por otra parte, el control interno del Ejecutivo Federal ha estado en diferentes instancias a través de la historia. ${ }^{31}$

\footnotetext{
${ }^{29}$ Idem.

${ }^{30}$ Véase: Diario Oficial de la Federación de 30 de julio de 1999.

${ }^{31}$ Solares Mendiola, Manuel, op. cit., pp. 23-24.
} 
Actualmente con las reformas constitucional y legal de 27 de mayo de 2015 y 18 de julio de 2016, respectivamente, se creó en México el Sistema Nacional Anticorrupción, como un mecanismo de coordinación entre todas instancias que se ocupan del combate a la corrupción.

\section{Antecedentes históricos del control gubernamental EN EL ECUADOR}

El Ecuador como organización jurídica fue fundado en 1830, época desde la cual han regido 20 constituciones ${ }^{32}$ que, acorde con el desenvolvimiento histórico, en lo relacionado con lo que actualmente se conoce como control de la utilización de los recursos estatales, ha adoptado la modalidad de Tribunal de Cuentas como ejecutor de los juicios de cuentas, las Contadurías y posteriormente la actividad de control atribuida a la Contraloría General de la República, entidad que entre 1928 y 1977 aplicó un régimen hacendario y de fiscalización y, con motivo de la actualización iniciada en esa época, instaurar el sistema al de control mediante auditoría gubernamental.

"La Constitución de 1830 contó con la participación de legisladores con sólidos conocimientos jurídicos y administrativos, y por ello se tomó muy en cuenta el sistema de control, que tenía que efectuarse sobre los fondos públicos. El artículo 55 dice: Habrá en la capital del Estado una Contaduría General, que revisará las cuentas de las Contadurías Departamentales. El Presidente de la República, como máxima autoridad administrativa, tenía la atribución de designar a los empleados de hacienda. El 28 de septiembre de 1830 se dictó la Ley de Hacienda. La Contaduría tenía un nexo muy estrecho con el Ministerio de Hacienda". ${ }^{33}$

${ }^{32}$ Ministerio de Relaciones Exteriores y Movilidad Humana, "Constituciones del Ecuador desde 1830 hasta 2008”, Cancillería del Ecuador, <http:/ /www.cancilleria.gob. ec/constituciones-del-ecuador-desde-1830-hasta-2008/>.

${ }^{33}$ Varios Autores, Reseña histórica de la Contraloría General del Estado del Ecua- 
"Alfredo Pareja Diezcanseco referido en la reseña histórica de la Contraloría General del Estado, señala que durante los tres Gobiernos del general Juan José Flores, la Hacienda Pública fue patrimonio de los militares. No hubiera podido Flores gobernar sin ellos y hubo que satisfacer sus apetitos para mantenerse en el poder. Esta fórmula de equilibrio del poder público quedó como una gravísima dolencia en nuestro país. Vivía el Ecuador en la miseria. El desorden financiero es la característica de sus administraciones". ${ }^{34}$

Al llegar al poder Vicente Rocafuerte, la situación administrativa del país era desastrosa. ${ }^{35}$ En cuanto a la hacienda pública, ni contabilidad, ni cuentas, ni recaudaciones ordenadas, ni dinero, solo desorden y picardía de los funcionarios. Justamente durante su gobierno se dieron los lineamientos para organizar el sistema administrativo, financiero y de control, mediante la expedición de la Ley Orgánica de Hacienda en el año de 1837. Desde aquel año se estableció un orden jerárquico, en cuya cúspide se encontraba el Presidente de la República; a continuación, venía el Ministerio de Hacienda, al que le correspondía la vigilancia de la administración de la hacienda pública y estaba facultado para tomar las medidas necesarias para mejorar la recaudación, distribución y administración de las rentas públicas, así como la conservación de los bienes nacionales.

Recibía de los gobernadores los estados mensuales que le presentaban las oficinas de recaudación y los estados comparativos trimestrales del producto de la renta. La Contaduría General le proporcionaba los datos necesarios para elaborar y elevar al Congreso el informe de su Secretaría. ${ }^{36}$ Como se puede observar la actividad de control era una oficina de una Secretaría de Estado, sin autonomía

dor, Cincuentenario de fundación (Quito: Contraloría General del Estado, 1977), pp. 63-64.

\footnotetext{
${ }^{34}$ Ibidem, p. 67.

${ }^{35}$ Ibidem., p. 69.

${ }^{36}$ Ibidem, pp. 69-71.
} 
e independencia.

En el gobierno del presidente García Moreno, se dicta la Ley Orgánica de Hacienda, la misma que fue promulgada el 21 de octubre de 1.863. Esta ley recoge las principales instituciones de sus predecesoras y es la de mayor duración en la vida del país, pues rigió por un total de 64 años, hasta 1927, en que se dicta una innovadora ley inspirada en los trabajos de la Misión Kemmerer, que fuera contratada por el presidente Isidro Ayora. Al corto tiempo, no sin antes haber sufrido considerables reformas, esta ley fue sustituida en 1928 por otra cuya vigencia también es significativa al extenderse por 47 años, hasta 1975, cuando se expide la ley que recoge los principios básicos de gerencia financiera y de control gubernamental moderno. Desde luego, la ley de hacienda de 1863 mereció codificaciones importantes en 1912 y 1924, y la de 1928 en 1947, 1948 y $1960^{37}$.

Con la llamada Revolución Juliana de 1925, comienza una transformación político-administrativa y socio-económica del país. Con ella se inician cambios tanto en lo económico como en lo tributario y administrativo. Con la filosofía de cambio, enunciada por la Revolución Juliana, el Gobierno ecuatoriano, presidido por Isidro Ayora, contrató a la Misión Kemmerer liderada por el Dr. Edwin Walter Kemmerer y conformada por expertos financieros norteamericanos, para el estudio y organización del estado económico de nuestro país. Entre las leyes que preparó fue la Ley Orgánica de Hacienda en 1928. ${ }^{38}$

En la exposición de motivos de la ley se dice que se establece la Contraloría, como departamento independiente del Gobierno. La Contraloría no podría cumplir sus funciones con toda la eficiencia, si estuviera subordinada a algún Ministerio como por ejemplo el de

${ }^{37}$ Sección nacional del Ecuador del IPGH, "Ley Orgánica de Administración Financiera y Control", Sección Nacional del Ecuador del IPGH, febrero del 2017. < http:// www.ipgh.gob.ec/ imagenes/noticias/pdfs/LOAFYC14.pdf>, p. 19.

${ }^{38}$ Varios Autores, Reseña histórica de la Contraloría General del Estado del Ecuador, Cincuentenario de fundación, p. 117. 
Hacienda, La Contraloría se constituye independiente del Poder Ejecutivo, principio jurídico administrativo esencial para el éxito de su función principal, que es la del control fiscal. La independencia y autonomía, está conforme con la práctica mundial de la fiscalización pública, así en los Estados Unidos se estableció en 1921 un departamento de Contraloría General, independiente del Poder Ejecutivo y bajo el control y dirección de un Contralor General, quien rinde cuentas únicamente ante el Congreso. Los poderes y deberes conferidos por la Ley al Contralor son iguales a los del Contralor General de los Estados Unidos. ${ }^{39}$

El Órgano Superior de Control en el Ecuador tiene dos etapas históricas bien marcadas: la primera, durante los siglos XIX y primer cuarto del siglo XX, en que la nota predominante es la jurisdiccional, configurándose como Contaduría y luego como Tribunal de Cuentas y vinculándose en forma amplia con el ámbito judicial; la segunda etapa, con una caracterización legislativa, en cuanto el Contralor es nombrado por el Congreso y responde ante dicho Órgano legislativo. La posición del Tribunal de Cuentas como órgano de tipo judicial arranca no solo de la Ley de Hacienda, sino de la propia Constitución; así, es posible observar que en las Cartas Políticas de 1878, 1884, 1897 y 1906, dentro del título denominado del Poder Judicial, se trata del Tribunal de Cuentas. ${ }^{40}$

La reforma sustancial de su actividad como órgano de control, da inicio el 10 de octubre de 1974, con la expedición del DecretoLey 1065-A, que reforma a la Ley Orgánica de Hacienda de 1928 y codificada de 1960 y posterior Ley Orgánica de Administración Financiera y Control, publicada en el R.O. 337 del 16 de mayo de 1977, se incorporó el enfoque sistémico de las ciencias administrativas, es decir al conjunto de componentes interrelacionados, interdependientes e interactuantes que tiene como finalidad el logro de

\footnotetext{
${ }^{39}$ Ibidem, p. 140.

${ }^{40}$ Ibidem, p. 35-36.
} 
objetivos determinados en un plan que, al caso está vinculada con la prestación de servicios públicos y el desarrollo socioeconómico de manera eficiente, efectiva y económica. ${ }^{41}$

Desde 1927 a 1973, la Contraloría General, baso su acción fundamentalmente en el sistema de contabilidad y control fiscal de los recursos públicos de manera aritmética: de lo gastado, comprado, entregado y ordenado.

Al cambiarse su estructura legal y administrativa, la contraloría dejo de ser la oficina de contabilidad de intervención fiscal, y se constituyó en un organismo superior de control, que tiene por finalidad el control externo de los recursos de las entidades del sector público; que lo efectúa mediante el examen posterior de las operaciones financieras y administrativas de cada entidad, por medio de exámenes especiales y auditoria gubernamental ${ }^{42}$

En la década de los 80 del siglo anterior, uno de los temas de discusión en la sociedad ecuatoriana fue la creación de la denominada Función de Control, ${ }^{43}$ para concentrar y elevar de categoría jurídica al control gubernamental, proposición que no se concretó mediante textos constitucionales o legales; por tanto, se mantuvo en el país la organización clásica de las Funciones del Estado y, a la Contraloría General del Estado, en la misma calidad constitucional de Organismo Técnico Superior de Control de los recursos públicos, dotado de autonomía e independencia para el ejercicio de esas facultades, acorde con los principios y normas universales existentes sobre esta materia.

${ }^{41}$ Ecuador, Ley Orgánica de Administración Financiera y Control, en Registro Oficial 337, Decreto Supremo 1429, "Resumen de los antecedentes", (Quito, 16 de mayo de 1977), pp. 55-56.

${ }^{42}$ Ibidem, p. 155.

${ }^{43}$ UNIANDES EPISTEME: Revista de Ciencia, Tecnología e Innovación. Carrera Calderón, F. A. Vol. (2) Núm. (1) 2015 Universidad Regional Autónoma de los Andes UNIANDES 1 La Participación Ciudadana y Control Social en Ecuador. Citizen Participation and Social Control in Ecuador. MSc. Frankz Alberto Carrera Calderón frankzcarrera@gmail.com UNIANDES. 
En la actualidad, la Constitución del Ecuador, publicada en el R.O. 449 de 20 de octubre de 2008, Capítulo V, crea la Función de Transparencia y Control Social, integrada por varias instituciones de control, de la que es parte la Contraloría General del Estado, señalando que se trata de un organismo técnico encargado del control de la utilización de los recursos estatales, y la consecución de los objetivos de las instituciones del Estado y de las personas de derecho privado que dispongan de recursos públicos. Además dirigir el sistema de control administrativo que se compone de las auditorías interna y externa y del control interno. Determinar responsabilidades administrativas y civiles culposas e indicios de responsabilidad penal y expedir la normativa para el cumplimiento de sus funciones. Finalmente asesorar a los órganos y entidades del Estado cuando se lo solicite. Le corresponde al Consejo de Participación Ciudadana y Control Social designar al Contralor General del Estado por concurso público y es el Contralor General el que designa a todas las autoridades de control, incluidos los auditores internos de todas las instituciones públicas, lo que evidencia un sistema de control totalmente concentrado.

\section{LOS MARCOS JURÍDICOS}

1. Base legal en la república de colombia

Actualmente el control externo en Colombia se regula en el artículo 117 de la Constitución Política de 1991, que estatuye a la Contraloría General de la República como órgano de control; en el 119 le asigna la "vigilancia de la gestión fiscal y el resultado de la administración”. Por su parte, el artículo 209 establece el control interno de la administración pública.

En términos del artículo 267 de la Constitución de 1991, la Contraloría General es una entidad de carácter técnico con autonomía administrativa y presupuestal. Ejerce el control fiscal que es una función pública y vigila la gestión fiscal de la Administración y de los 
particulares o entidades que manejen fondos o bienes de la Nación. Dicho control se ejercerá en forma posterior y selectiva conforme a los procedimientos, sistemas y principios que establezca la ley. Esta podrá, sin embargo, autorizar que, en casos especiales, la vigilancia se realice por empresas privadas colombianas escogidas por concurso público de méritos, y contratadas previo concepto del Consejo de Estado.

La vigilancia de la gestión fiscal incluye el ejercicio de un control financiero, de gestión y de resultados, fundado en la eficiencia, la economía, la equidad y la valoración de los costos ambientales. Excepcionalmente, podrá ejercer control posterior sobre cuentas de cualquier entidad territorial. El Contralor será elegido por el Congreso para un período igual al del Presidente de la República, de terna integrada por candidatos de la Corte Constitucional, la Corte Suprema de Justicia y el Consejo de Estado, y no podrá ser reelegido para el período inmediato ni continuar en ejercicio de sus funciones al vencimiento del mismo.

Quien haya ejercido este cargo no podrá desempeñar empleo público alguno del orden nacional, salvo la docencia, ni aspirar a cargos de elección popular sino un año después de haber cesado en sus funciones.

Para ser elegido Contralor General de la República se requiere ser colombiano de nacimiento y en ejercicio de la ciudadanía; tener más de 35 años de edad; tener título universitario; o haber sido profesor universitario durante un tiempo no menor de 5 años; y acreditar las calidades adicionales que exija la Ley. No podrá ser elegido Contralor General quien sea o haya sido miembro del Congreso u ocupado cargo público alguno del orden nacional, salvo la docencia, en el año inmediatamente anterior a la elección. Tampoco podrá ser elegido quien haya sido condenado a pena de prisión por delitos comunes.

En el artículo 268 se regulan las atribuciones del Contralor General de la República: 1) prescribir los métodos y formas de rendir cuentas; 2) revisar y fenecer las cuentas que deben llevar los respon- 
sables del erario y determinar el grado de eficiencia, eficacia y economía con que hayan obrado; 3)llevar un registro de la deuda pública de la Nación y de las entidades territoriales; 4) exigir informes sobre su gestión fiscal a los empleados oficiales de cualquier orden y a toda persona o entidad pública o privada que administre fondos o bienes de la Nación; 5) establecer la responsabilidad que se derive de la gestión fiscal, imponer las sanciones pecuniarias que sean del caso, recaudar su monto y ejercer la jurisdicción coactiva sobre los alcances deducidos de la misma; 6) conceptuar sobre la calidad y eficiencia del control fiscal interno de las entidades y organismos del Estado; 7) presentar al Congreso de la República un informe anual sobre el estado de los recursos naturales y del ambiente; 8) podrá exigir, la suspensión de funcionarios mientras culminan las investigaciones o los respectivos procesos penales o disciplinarios; 9) presentar proyectos de ley relativos al régimen del control fiscal; 11) presentar informes al Congreso y al Presidente de la República sobre el cumplimiento de sus funciones y certificación sobre la situación de las finanzas del Estado, de acuerdo con la ley, y 13) (...) Presentar a la Cámara de Representantes la Cuenta General de Presupuesto y del Tesoro y certificar el balance de la Hacienda presentado al Congreso.

También se establece la reserva de ley en lo que se refiere a la organización, formas y sistemas de participación ciudadana que permitan vigilar la gestión pública (art. 270); se establece el valor probatorio de las indagaciones de la contraloría (art. 271); además, se prescribe que la vigilancia de la gestión fiscal de los departamentos, distritos y municipios donde haya contralorías, corresponde a éstas y se ejercerá en forma posterior y selectiva. La de los municipios incumbe a las contralorías departamentales, salvo lo que la ley determine respecto de contralorías municipales. Corresponde a las asambleas y a los concejos distritales y municipales organizar las respectivas contralorías como entidades técnicas dotadas de autonomía administrativa y presupuestal. Igualmente les corresponde 
elegir contralor, además, pueden contratar con empresas privadas colombianas el ejercicio de la vigilancia fiscal (ART. 272). Por último, la vigilancia de la gestión fiscal de la Contraloría General se ejercerá por un auditor elegido para períodos de dos años por el Consejo de Estado, de terna enviada por la Corte Suprema de Justicia. La ley determinará la manera de ejercer dicha vigilancia a nivel departamental, distrital y municipal (art. 274). ${ }^{44}$

\section{Base legal en México}

Además, del contenido del Título Cuarto "De las Responsabilidades de los Servidores Públicos, Particulares Vinculados con Faltas Administrativas Graves o Hechos de Corrupción, y Patrimonial del Estado", artículos 108 a 114, de la Constitución Política de los Estados Unidos Mexicanos, encontramos al artículo 73, fracciones XXIV y XXVIII, en lo que se refiere a las facultades del Congreso de la Unión para expedir las leyes que regulen la organización y facultades de la Auditoría Superior de la Federación y las demás que normen la gestión, control y evaluación de los Poderes de la Unión y de los entes públicos federales; así como para expedir la ley general que establezca las bases de coordinación del Sistema Nacional Anticorrupción; y para expedir leyes en materia de contabilidad gubernamental que regirán la contabilidad pública y la presentación homogénea de información financiera, de ingresos y egresos, así como patrimonial, a nivel nacional. También el artículo 74, fracciones II y VI, en lo que se refiere a las facultades exclusivas de la Cámara de Diputados en materia de coordinación y evaluación del desempeño de las funciones de la Auditoría Superior de la Federación; la revisión de la cuenta pública y designar, por el voto de las dos terceras partes de sus miembros presentes, a los titulares de los órganos internos de control

${ }^{44}$ GEORGETOWN "Constitución política de Colombia”, Georgetown University, 17 de junio de 2010, Consulta: 08 noviembre 2015, <http://pdba.georgetown. edu/Constitutions/Colombia/colombia91.pdf> 
de los organismos con autonomía reconocida en esta Constitución que ejerzan recursos del Presupuesto de Egresos de la Federación.

En lo que se refiere al control externo de su administración pública, la Constitución Política de los Estados Unidos Mexicanos establece en su artículo 79 que la Auditoría Superior de la Federación de la Cámara de Diputados, tendrá autonomía técnica y de gestión en el ejercicio de sus atribuciones y para decidir sobre su organización interna, funcionamiento y resoluciones, en los términos que disponga la ley. Podrá iniciar el proceso de fiscalización a partir del primer día hábil del ejercicio fiscal siguiente, sin perjuicio de que las observaciones o recomendaciones que, en su caso realice, deberán referirse a la información definitiva presentada en la Cuenta Pública. Asimismo, por lo que corresponde a los trabajos de planeación de las auditorías, podrá solicitar información del ejercicio en curso, respecto de procesos concluidos (...).

A la Auditoría Superior de la Federación se le otorgan facultades para: fiscalizar en forma posterior los ingresos, egresos y deuda; las garantías que, en su caso, otorgue el Gobierno Federal respecto a empréstitos de los Estados y Municipios; el manejo, la custodia y la aplicación de fondos y recursos de los Poderes de la Unión y de los entes públicos federales, así como realizar auditorías sobre el desempeño en el cumplimiento de los objetivos contenidos en los programas federales, a través de los informes que se rendirán en los términos que disponga la Ley.

También tiene competencia para fiscalizar directamente los recursos federales que administren o ejerzan los estados, los municipios, el Distrito Federal y los órganos político-administrativos de sus demarcaciones territoriales. Además, puede solicitar y revisar, de manera casuística y concreta, información de ejercicios anteriores al de la Cuenta Pública en revisión, sin que por este motivo se entienda, para todos los efectos legales, abierta nuevamente la Cuenta Pública del ejercicio al que pertenece la información solicitada, exclusivamente cuando el programa, proyecto o la erogación, con- 
tenidos en el presupuesto en revisión abarque para su ejecución y pago diversos ejercicios fiscales o se trate de revisiones sobre el cumplimiento de los objetivos de los programas federales. Se destaca que las observaciones y recomendaciones que, respectivamente, la Auditoría Superior de la Federación emita, sólo podrán referirse al ejercicio de los recursos públicos de la Guenta Pública en revisión.

Además, en las situaciones que determine la Ley, derivado de denuncias, previa autorización de su Titular, podrá revisar durante el ejercicio fiscal en curso a las entidades fiscalizadas, así como respecto de ejercicios anteriores. Las entidades fiscalizadas proporcionarán la información que se solicite para la revisión, en los plazos y términos señalados por la Ley y, en caso de incumplimiento, serán aplicables las sanciones legales.

A la Auditoría Superior de la Federación se le obliga a rendir un informe específico a la Cámara de Diputados y, en su caso, promover las acciones que correspondan ante el Tribunal Federal de Justicia Administrativa, la Fiscalía Especializada en Combate a la Corrupción o las autoridades competentes. También debe entregar el último día hábil de los meses de junio y octubre, así como el 20 de febrero del año siguiente al de la presentación de la Cuenta Pública, los informes individuales de auditoría que concluya durante el periodo respectivo. Asimismo, en esta última fecha, entregar el Informe General Ejecutivo del Resultado de la Fiscalización Superior de la Cuenta Pública, el cual se someterá a la consideración del Pleno de dicha Cámara. El Informe General Ejecutivo y los informes individuales serán de carácter público y tendrán el contenido que determine la ley; estos últimos incluirán como mínimo el dictamen de su revisión, un apartado específico con las observaciones de la Auditoría Superior, así como las justificaciones y aclaraciones que, en su caso, las entidades fiscalizadas hayan presentado sobre las mismas. 
Por lo anterior, la Auditoría Superior de la Federación deberá entregar a la Cámara de Diputados, los días 1 de los meses de mayo y noviembre de cada año, un informe sobre la situación que guardan las observaciones, recomendaciones y acciones promovidas, correspondientes a cada uno de los informes individuales de auditoría que haya presentado en los términos de esta fracción. La Auditoría Superior de la Federación deberá guardar reserva de sus actuaciones y observaciones hasta que rinda los informes individuales de auditoría y el Informe General Ejecutivo a la Cámara de Diputados.

También tiene competencia para investigar los actos u omisiones que impliquen alguna irregularidad o conducta ilícita en el ingreso, egreso, manejo, custodia y aplicación de fondos y recursos federales, y efectuar visitas domiciliarias, únicamente para exigir la exhibición de libros, papeles o archivos indispensables para la realización de sus investigaciones, sujetándose a las leyes y a las formalidades establecidas para los cateos. En este sentido, si derivado de sus investigaciones, promover las responsabilidades que sean procedentes ante el Tribunal Federal de Justicia Administrativa y la Fiscalía Especializada en Combate a la Corrupción. El Poder Ejecutivo Federal aplicará el procedimiento administrativo de ejecución para el cobro de las indemnizaciones y sanciones pecuniarias.

Al titular de la Auditoría Superior de la Federación lo designa la Cámara de Diputados por el voto de las dos terceras partes de sus miembros presentes, de conformidad con la ley, durará en su encargo ocho años y podrá ser nombrado nuevamente por una sola vez. ${ }^{45}$

\section{BAse legal de LA REPÚBLica del eCuAdor}

Por mandato constitucional, el pueblo es el mandante y primer fiscalizador del poder público. La Función de Transparencia y Con-

${ }^{45}$ Cámara de diputados del H. Congreso de la Unión, "Constitución política de los Estados Unidos Mexicanos", 24 de agosto del 2019, < http://www.diputados.gob. mx/LeyesBiblio/pdf/1_090819.pdf >. 
trol Social promoverá e impulsará el control de las entidades y organismos del sector público, dicha Función está integrada por varias instituciones de control, entre ellas, el Consejo de Participación Ciudadana y la Contraloría General del Estado.

Le corresponde al Consejo de Participación Ciudadana designar al Contralor General del Estado, para cumplir esta atribución organizará comisiones ciudadanas de selección, que serán las encargadas de llevar a cabo el concurso público de oposición y méritos con postulación, veeduría y derecho a impugnación ciudadana.

Estas comisiones de selección se integrarán por un delegado de cada Función del Estado e igual número de representantes por las organizaciones sociales y la ciudadanía.

El Consejo de Participación ciudadana escogerá a quien obtenga la mejor puntuación e informará a la Asamblea Nacional para la posesión respectiva.

Serán funciones de la Contraloría General del Estado, dirigir el sistema de control administrativo que se compone de auditoría interna, auditoría externa y del control interno de las entidades del sector público y de las entidades privadas que disponen de recursos públicos.

Entre sus funciones también consta la de determinar responsabilidades administrativas y civiles culposas e indicios de responsabilidad penal, relacionados con los aspectos y gestiones sujetas a su control; así como expedir normativa para el cumplimiento de sus fines. El Contralor General del Estado ejercerá sus funciones durante un período de cinco años. ${ }^{46}$

Si bien las disposiciones constitucionales relacionadas a la competencia de la Contraloría son escuetas, es evidente que su competencia es integral pues se trata de un sistema concentrado de control que agrupa a las auditorías externa e interna, así como el control interno. Lo que por un lado, estaría garantizando los principios de

${ }^{46}$ Constitución de la República del Ecuador, Arts: 204, 205, 208, 209, 210,211 y 212. 
autonomía e independencia de la actividad de control; y por otro lado, al concentrarse el sistema de control también se concentra el poder, pues debemos tener claro de que el control es parte del propio poder del Estado.

\section{CONCLUSIONES}

Al finalizar el presente trabajo de investigación se tiene que los modelos jurídicos de México, Colombia y Ecuador tuvieron directa influencia de la familia jurídica germano romana, en la época de la colonia, prácticamente fue un trasplante y más que ello fue una imposición en los territorios invadidos y dominados por la Corona española.

En la época de la colonia, no existieron sistemas de control gubernamental orientados a mantener finanzas públicas sanas en beneficio de la colectividad, el único objetivo de la Corona española y sus conquistadores fue saquear la riqueza de los pueblos coloniales en su propio beneficio y nada más, se limitó al cobro de los tributos impuestos a los pueblos conquistados.

Con la revolución francesa se produce de manera definitiva el tránsito del Estado monárquico al Estado liberal, caracterizado por la división del poder en funciones, en una relación de pesos y contrapesos, de lo que se deriva el necesario desarrollo de la actividad de control del poder, por lo que su rol es determinante en las relaciones jurídico administrativas entre la función pública y los ciudadanos, así como en el sostenimiento de la institucionalidad pública y la naciente democracia.

La revolución francesa tuvo una gran influencia a nivel mundial y con ella surgen las luchas por la independencia, las nacientes repúblicas se inician en condiciones económicas deplorables, esto provocó un gran desorden social y económico, sumado a las dos guerras mundiales, agudizaron la crisis en nuestra Región. En tales circunstancias surge la necesidad de reestructurar las finanzas públicas y privadas e implementar programas encaminados a mejorar 
la eficiencia y eficacia en el gasto público y a establecer criterios de productividad económica y social de corte liberal.

Para superar la crisis, sin duda era necesario implementar mecanismos de control fiscal que permita a los nuevos Estados ordenar sus finanzas, para estos efectos han venido implementando sistemas de control administrativo de los recursos públicos, que han variado a lo largo de la historia fundamentalmente en cuanto a la conformación de los controles internos y externos, la designación de las autoridades de control, su ámbito y jurisdicción y los grupos de poder que los postulan.

Las dificultades que se dejan anotadas no hizo posible el trasplante puro o completo de tal o cual modelo jurídico, se tomaron figuras jurídicas de uno y otro de acuerdo a los intereses de los grupos dominantes locales y a los espacios de discusión social de los distintos grupos sociales de acuerdo a sus propias necesidades, lo que favoreció la creación de modelos jurídicos propios que surgen en base a nuestras propias realidades sociales, económicas y culturales.

En la actualidad los marcos jurídicos de los tres países en análisis marcan en forma clara tanto diferencias como semejanzas. Así, tanto en Ecuador como en Colombia, es posible ejercer el control por medio de empresas privadas. La diferencia es que en Colombia únicamente se lo puede hacer con empresas privadas nacionales y previo el visto bueno del Consejo de Estado, lo cual marca una forma de control adicional.

En cuanto a la forma de designación de las Autoridades de Control, en los tres países son totalmente diferentes. En Ecuador es consecuencia de un concurso público llevado a cabo por el Consejo de Participación Ciudadana y Control Social. En cambio en México y Colombia elige la Función Legislativa, pero en Colombia la terna estará integrada por candidatos de la Corte Constitucional, Corte Suprema de Justicia y Consejo de Estado. Pero una vez elegidas las autoridades de control quien las controla, en el caso ecuatoriano por tener un sistema concentrado, que incluye la designación de 
su auditor interno, no es posible el control de su gestión; a diferencia del caso colombiano cuya actividad de control en cuanto a su desempeño está a cargo de un auditor interno designado por el Consejo de Estado.

Acorde con lo anterior, es importante para nuestros pueblos generar mecanismos de control de quienes ejercen la actividad de control. Debe destacarse que en Ecuador y México es la Función Legislativa la que ejerce un control político, pero no existe un control interno que nos permita evaluar de manera técnica el desempeño de las Autoridades de Control, básicamente sobre el cumplimiento eficiente y efectivo de sus facultades y atribuciones, así como de sus metas y objetivos de manera periódica.

Si bien las disposiciones constitucionales relacionadas a la competencia de la Contraloría son escuetas en Ecuador, es evidente que se trata de un sistema concentrado de control que agrupa a las auditorías externa e interna, así como el control interno, a diferencia de los textos constitucionales que norman las actividades de control de México y Colombia que son amplios y desconcentran las actividades de control.

Con la finalidad de precautelar la autonomía e independencia del candidato y posterior autoridad de control, únicamente en Colombia se tiene como requisito que no podrá ser candidato quien sea o haya sido miembro del Congreso u ocupado cargo público alguno del orden nacional, en el año inmediatamente anterior a la elección. Asimismo quien haya ejercido este cargo no podrá desempeñar empleo público alguno del orden nacional, salvo la docencia, ni aspirar a cargos de elección popular sino un año después de haber cesado en sus funciones.

La fiscalidad ambiental se registra en la constitución colombiana, lo cual debemos destacar ante la presión del libre comercio internacional y la indiscriminada explotación de los recursos naturales. Es el Estado y sus instituciones los responsables de dictar políticas públicas orientadas a proteger y controlar los contratos de concesión 
y la relación jurídica administrativa de los recursos naturales; y, son las autoridades de control las que deben ejercer el control externo sobre el cumplimiento de las metas y objetivos de las autoridades públicas relacionadas con el control de dichos recursos.

Finalmente, el ordenamiento jurídico mexicano pone especial cuidado en el control de la gran cuenta pública y es de destacar la prolijidad que incluye fechas de presentación del estado de situación financiera, cuando señala que la Auditoría Superior de la Federación presentará el Informe General Ejecutivo del Resultado de la Fiscalización Superior de la Cuenta Pública, el 20 de febrero del año siguiente al de la presentación de la Cuenta Pública, a consideración del Pleno de Cámara de Diputados, el mismo que será de carácter público; En igual sentido, en Colombia, la Autoridad de Control tiene la obligación de presentar a la Cámara de Representantes la Cuenta General de Presupuesto y del Tesoro y certificar el balance de la Hacienda presentado al Congreso. En el Ecuador, no existe autoridad que pueda pronunciarse sobre el estado de situación financiera de la gran cuenta pública y al no existir este balance financiero sin lugar a dudas se caotiza el manejo de los fondos públicos.

Los esfuerzos de los diversos grupos sociales y políticos por construir mecanismos de controles eficientes y eficaces para combatir la corrupción han sido permanentes, pero este fenómeno es más complejo, en razón de que existe una multiplicidad de elementos involucrados: social, político, económico, psicológico, etc. El control únicamente visibiliza los actos de corrupción, lo cual no es suficiente para combatirla, hace falta la participación decidida de todos quienes integramos la Sociedad. 
V. FUENTES CONSULTADAS

1. Bibliografía

Dromi, Roberto, Derecho Administrativo, Tomo I, Buenos Aires, Hispana Libros, 2015.

Gómez Latorre, Armando, Antecedentes Históricos de la Contraloría. Bogotá, Revista de la Contraloría General del Estado, núm, 150. 1983.

Jaramillo Uribe, Jaime, Manual de Historia de Colombia, Bogotá, Pro-Cultura Instituto Colombiano de Cultura, 1982.

Loewenstein Karl, Teoría de la Constitución, España, Ariel, 1976.

Márquez Gómez, Daniel, Función Furidica del Control de la Administración Pública, México, Universidad Autónoma de México, 2005.

Montaña Pinto, Juan, Teoría Utópica de las Fuentes del Derecho ecuatoriano, Quito, Centro de Estudios y Difusión Constitucional de la Corte Constitucional del Ecuador para la Transición, 2012.

Nieto, Santiago y Medina Pérez, Yamille, Control Externo y Responsabilidad de los Servidores Públicos, México, Universidad Nacional Autónoma de México, 2005.

Otscapdequi, J.M, El Estado español de las Indias, México, Fondo de Cultura Económica, 1982.

Rodríguez Becerra, Carlos, La Gestión, el Control y la Responsabilidad Fiscal de la Administración Pública en Colombia, Bogotá, Grupo Editorial Ibañez, 2011.

Solares Mendiola, Manuel, La Auditoría Superior de la Federación, México, Universidad Autónoma de México, 2004.

Uniandes Episteme, Revista de Ciencia, Tecnología e Innovación, Carrera Calderón, F. A. Vol. (2) Núm. (1) 2015 Universidad Regional Autónoma de los Andes UNIANDES 1 La Participación Ciudadana y Control Social en Ecuador. Citizen Participation and Social Control in Ecuador, MSc. Frankz Alberto Carrera Calderón frankzcarrera@gmail.com UNIANDES. 
Valadés, Diego, El Control del Poder, México, Porrúa, 2006.

Younes Moreno, Diego, Régimen de Control Fiscal, Bogotá, Temis, 1987.

2. Legisgrafía

Constitución de la República del Ecuador.

Constitución Política de los Estados Unidos Mexicanos.

Constitución de Colombia.

Ley de Hacienda.

Ley Orgánica de Administración Financiera y Control.

Ley Orgánica de la Contraloría General del Estado.

3. Electrónicas

<http://www.flacsoandes.edu.ec/libros/digital/53326.pdf>.

<http://www.asambleanacional.gob.ec/sites/default/files/documents/old/constituciondebolsillo.pdf> .

<http://www.diputados.gob.mx/LeyesBiblio/htm/1.htm>.

<http://pdba.georgetown.edu/Constitutions/Colombia/colombia91.pdf>. 
